\title{
How can neurological outcomes be predicted in comatose pediatric patients after out-of-hospital cardiac arrest?
}

\author{
Hyo Jeong Kim, MD, PhD \\ Department of Pediatrics, Gachon University Gil Medical Center, Gachon University College of Medicine, Incheon, Korea
}

The prognosis of patients who are comatose after resuscitation remains uncertain. The accurate prediction of neurological outcome is important for management decisions and counseling. A neurological examination is an important factor for prognostication, but widely used sedatives alter the neurological examination and delay the response recovery. Additional studies including electroencephalography, somatosensoryevoked potentials, brain imaging, and blood biomarkers are useful for evaluating the extent of brain injury. This review aimed to assess the usefulness of and provide practical prognostic strategy for pediatric postresuscitation patients. The principles of prognostication are that the assessment should be delayed until at least 72 hours after cardiac arrest and the assessment should be multimodal. Furthermore, multiple factors including unmeasured confounders in individual patients should be considered when applying the prognostication strategy.

Keywords: Out-of-hospital cardiac arrest, Child, Prognosis, Electroencephalography, Computed tomography

\section{Introduction}

Resuscitation following cardiac arrest and postcardiac arrest care have significantly improved in recent years. However, mortality and poor outcomes remain prevalent in pediatric out-ofhospital cardiac arrest (OHCA) patients. A study performed from 2007 to 2012 in the United States ${ }^{1)}$ reported a current return of spontaneous circulation (ROSC) rate of $36.4 \%$ and an annual survival rate of OHCA patients after discharge of 6.7\%-10.2\%. In Korea, according to an epidemiologic study performed from 2008 to 2012, the overall rates for admission and discharge survival of pediatric OHCA patients were 35.2\% and $12.8 \%$, respectively. ${ }^{2}$ The prognosis of patients admitted in a comatose state after successful resuscitation remains uncertain for a period of time. Eventually, only a few patients survive with variable neurological complications. Death or poor outcomes mainly occur because of hypoxic-ischemic brain injury.

Predicting neurological outcomes is essential for facilitating management decisions and parental counseling. Accurate prog. nostication is important for avoiding pursuing useless prolonged treatments in patients who inevitably suffer poor outcomes and avoiding inappropriate withdrawal of life-sustaining treatments in patients who show the potential for neurological recovery.

However, determining prognosis in pediatric resuscitated patients is complex because no single test can reliably predict it. Variable confounding factors can influence each individual's prognosis. In addition, therapeutic hypothermia complicates prognostic evaluations because of prolonged sedation. A neurological evaluation alone cannot predict prognosis. Additional tools such as electroencephalography (EEG), somatosensoryevoked potential (SSEP), neuroimaging, and blood biomarkers can help clinicians evaluate the extent of brain injury and establish the prognosis. A multimodal strategy based on a neurological examination and advanced diagnostic methods should be considered for use in prognostication.

The 2015 guidelines of postcardiac arrest care by the American Heart Association (AHA) and the European Resuscitation Council (ERC) and the European Society of Intensive Care Medicine (ESICM) for postresuscitation care provide detailed recommendations for prognostication after cardiac arrest in adult patients. ${ }^{3,4)}$ However, there are currently no well-organized guidelines for postresuscitation prognostication in pediatric patients. A recent scientific statement by the AHA summarized the consensus about prognostication for ROSC after cardiac arrest in pediatric patients. ${ }^{5)}$

This review delineates the usefulness of prognostication modalities for pediatric postresuscitation patients and provides practical multimodal approaches on how and when to use these modalities to ensure the reliable and accurate prediction of treatment outcomes. This review mainly referred to the AHA pediatric consensus statement, but the 2015 AHA or $2015 \mathrm{ERC/}$ ESICM adult guidelines were also referred to in the event that the pediatric data were lacking.

Corresponding author: Hyo Jeong Kim, MD, PhD. Department of Pediatrics, Gachon University Gil Medical Center, Gachon University College of Medicine, 21, Namdongdaero 774 beon-gil, Namdong-gu, Incheon 21565, Korea

凶 E-mail: greatelena@naver.com, https://orcid.org/0000-0003-2191-5341

Received: 11 August, 2019, Revised: 3 October, 2019, Accepted: 7 october, 2019

This is an open-access article distributed under the terms of the Creative Commons Attribution Non-Commercial License (http://creativecommons.org/licenses/by$\mathrm{nc} / 4.0 /$ ) which permits unrestricted non-commercial use, distribution, and reproduction in any medium, provided the original work is properly cited.

Copyright (c) 2020 by The Korean Pediatric Society 


\section{Outcome assessment}

The Pediatric Cerebral Performance Category (PCPC) and Pediatric Overall Performance Category (POPC) scales are the most commonly used tools to measure pediatric cardiac arrest outcomes. PCPC and POPC were developed to enable the easy assessment of the general functional morbidity and degree of cognitive impairment after a critical illness or injury. ${ }^{6,7)}$ PCPC measures neurologic function, whereas POPC focuses on overall health and functional morbidity including neurologic function (Table 1). PCPC scales of 1-3 are considered favorable neurologic outcomes, while PCPC scales of 4-6 are considered unfavorable neurologic outcomes. Recently, the Collaborative Pediatric Critical Care Research Network developed and validated the Functional Status Scale (FSS), which applies to hospitalized pediatric patients across a wide spectrum of ages and inpatient environments. ${ }^{8)}$ The FSS has 6 domains: mental status, sensory functioning, communication, motor functioning, feeding, and respiratory status. Each domain is categorized into normal, mild dysfunction, moderate dysfunction, severe dysfunction, and very severe dysfunction (Table 1). The total scores are 6-30.8)

\section{Clinical neurological examination}

Predicting an outcome based on a clinical neurological examination may be challenging. Factors such as the effect of sedatives, physiological states such as hypotension or metabolic abnormalities, and the child's developmental age should also be considered when making a prognosis. Targeted temperature management (TTM) also influences the neurological examination. It is important to assess which specific neurologic sign can accurately predict the outcome at a specific time.

The American Academy of Neurology concluded that the absence of a pupillary light response or corneal reflexes, and no motor or extensor response to pain until 3 days after cardiac arrest was predictive of an unfavorable neurologic outcome in adult patients based on a systematic review. ${ }^{9)}$

With regard to the timing of outcome prediction in adults, the 2015 AHA guidelines recommend that clinicians wait a minimum of 72 hours after ROSC to prognosticate an unfavorable outcome by a neurologic examination to minimize the rate of false positive results in patients who are not treated with TTM. Clinicians are recommended to wait until after the return of normothermia in patients who are treated with TTM. ${ }^{3)}$ The time until prognostication may be even longer if the residual effects of sedation confound the clinical neurological examination. ${ }^{3)}$ The 2015 ERC/ESICM guidelines also state that the earliest time a conclusive assessment should be made is at least 72 hours after ROSC. $^{4)}$

Unfortunately, there are no guidelines or high-quality evidence to support the use of neurological examination findings for prognostication in children following cardiac arrest. Rather, only a few small cohort studies have been conducted on this topic. In a study that included 44 children who had cardiac arrests, the clinical features of a Glasgow Coma Scale score $<5$, the absence of spontaneous respiratory activity, and the absence of pupillary reflexes at 24 hours after ROSC had a 100\% positive predictive value of an unfavorable outcome. ${ }^{10)}$ In a study comprising 35 children treated with TTM after cardiac arrest, the absence of motor and pupillary responses during hypothermia and soon after ROSC did not predict an unfavorable outcome, whereas the absence of these responses during normothermia predicted an unfavorable outcome. ${ }^{11)}$

The absence of a pupillary light response or motor response to pain is among the prognostic factors, but it can be changed to a reactive response over time with or without TTM, especially in the early period of ROSC. Therefore, the timing of pro-

Table 1. Outcome assessment scale

\begin{tabular}{|c|c|c|c|c|c|}
\hline & \multicolumn{2}{|c|}{ Pediatric Cerebral Performance Category Scale (PCPC) } & \multicolumn{2}{|c|}{ Pediatric Overall Performance Category Scale } & \multirow{2}{*}{ Functional Status Scale } \\
\hline & Category & Description & Category & Description & \\
\hline 1 & Normal & Normal at age-appropriate level & $\begin{array}{l}\text { Good overall perfor- } \\
\text { mance }\end{array}$ & $\begin{array}{l}\text { Healthy, alert, and capable of normal } \\
\text { activities of daily life }\end{array}$ & $\begin{array}{l}\text { Normal (1) } \\
\text { Mild dysfunction (2) }\end{array}$ \\
\hline 2 & Mild disability & $\begin{array}{l}\text { Conscious, alert, and able to interact } \\
\text { at age-appropriate level, possibility } \\
\text { of mild neurologic deficit }\end{array}$ & Mild overall disability & $\begin{array}{l}\text { Minor physical problem that is still com- } \\
\text { patible with normal life; conscious and } \\
\text { able to function independently }\end{array}$ & $\begin{array}{l}\text { Moderate dysfunction (3) } \\
\text { Severe dysfunction (4) } \\
\text { Very severe dysfunction (5) }\end{array}$ \\
\hline 3 & $\begin{array}{l}\text { Moderate dis- } \\
\text { ability }\end{array}$ & $\begin{array}{l}\text { Conscious, sufficient cerebral func- } \\
\text { tion for age-appropriate indepen- } \\
\text { dent activities of daily life, special } \\
\text { education of learning deficit pre- } \\
\text { sent }\end{array}$ & $\begin{array}{l}\text { Moderate overall dis- } \\
\text { ability }\end{array}$ & $\begin{array}{l}\text { Moderate disability from noncerebral or } \\
\text { cerebral system dysfunction; conscious } \\
\text { and performs independent activities of } \\
\text { daily life but is disabled for competitive } \\
\text { performance in school }\end{array}$ & $\begin{array}{l}\text { Mental status 1-5 } \\
\text { Sensory 1-5 } \\
\text { Communication 1-5 } \\
\text { Motor function 1-5 } \\
\text { Feeding 1-5 } \\
\text { Respiratory 1-5 }\end{array}$ \\
\hline 4 & $\begin{array}{l}\text { Severe dis- } \\
\text { ability }\end{array}$ & $\begin{array}{l}\text { Conscious; dependent on others for } \\
\text { daily support }\end{array}$ & $\begin{array}{l}\text { Severe overall dis- } \\
\text { ability }\end{array}$ & $\begin{array}{l}\text { Severe disability from noncerebral or } \\
\text { cerebral system dysfunction; consci- } \\
\text { ous but dependent on others for acti- } \\
\text { vities of daily living support }\end{array}$ & Total scores 6-30 \\
\hline 5 & $\begin{array}{l}\text { Coma or vege- } \\
\text { tative state }\end{array}$ & $\begin{array}{l}\text { Any degree of coma without the pre- } \\
\text { sence of all brain death criteria }\end{array}$ & $\begin{array}{l}\text { Coma or vegetative } \\
\text { state }\end{array}$ & $\mathrm{PCPC}=5$ & \\
\hline 6 & Brain death & $\begin{array}{l}\text { Apnea, areflexia, and/or electroen- } \\
\text { cephalographic silence }\end{array}$ & Brain death & $\mathrm{PCPC}=6$ & \\
\hline
\end{tabular}


gnostication should be delayed to at least 72 hours after ROSC to improve the reliability of the neurological examination in predicting the outcome. Furthermore, considering the limitations of the neurological examination in children after cardiac arrest, the findings of the examination alone should not be used to make a prognosis; supporting assessments such as electrophysiological tests, neuroimaging tests, and blood biomarkers should be considered as well.

\section{Electrophysiological tests}

\section{Somatosensory-evoked potentials}

SSEPs can be measured at the bedside and are less affected by sedative drugs or TTM than EEG or neurological examinations. However, SSEP recording requires a certain skill level to avoid artifacts. The absence of a bilateral N20 wave in adult comatose patients 3 days after cardiac arrest predicted an unfavorable outcome. ${ }^{9)}$ The 2015 AHA guidelines state that it is reasonable to consider an absent bilateral N20 SSEP wave 24-72 hours after cardiac arrest or after rewarming in comatose adult patients as a predictor of a poor outcome. ${ }^{3)}$

In a small cohort pediatric study of hypoxic-ischemic encephalopathy, the bilateral absence of N20 at 24 hours after admission had a $100 \%$ positive predictive value. ${ }^{10)}$ However, pediatric data of SSEPs and SSEPs after TTM treatment are very limited. At present, there is insufficient evidence to support the routine use of SSEP for prognostication in pediatric cardiac arrest patients. SSEP should be considered in the overall clinical context with other tests.

\section{Electroencephalography}

EEG is the most commonly used prognostic tool after cardiac arrest because it provides information about brain function and encephalopathy severity. Performing an EEG test after cardiac arrest, however, is advocated for both prognostication and the detection of convulsive and nonconvulsive seizures. Nonconvulsive status epilepticus is common after hypoxic-ischemic encephalopathy, for which continuous EEG is recommended to timely detect seizures. ${ }^{12)}$ However, in institutes lacking facilities and technical or interpreting staff, repeated routine EEG is used instead. EEG data can be obtained non-invasively at the bedside; however, technical expertise is required to obtain high-quality EEG readings, gain information on clinical status such as the use of sedative medication, and check for scalp edema or other possible artifacts. Further, trained interpreters are important for accurate test interpretation.

The 2015 AHA guidelines and 2015 ERC/ESICM guidelines for adults concluded that the persistent absence of EEG reactivity, burst-suppression at 72 hours or more after cardiac arrest or after rewarming, and status epilepticus in the absence of EEG reactivity predict a poor neurologic outcome. However, the lack of standardized EEG terminology in many studies has been raised as a limitation in the comparison and classification of EEG.

To overcome this problem, standardized EEG interpretation according to the terminology proposed by the American Clinical Neurophysiology Society (ACNS) ${ }^{13)}$ was performed to identify a prognostic EEG pattern. ${ }^{14)}$ According to the ACNS EEG terminology, a value above $20 \mu \mathrm{V}$ is considered normal voltage, while that below $10 \mu \mathrm{V}$ is defined as suppression. Regarding continuity, periods of suppression or attenuation of $10 \%-49 \%$ are defined as discontinuous, while those more than 50\% are defined as burst-suppression (below $10 \mu \mathrm{V}$ ) or burst-attenuation

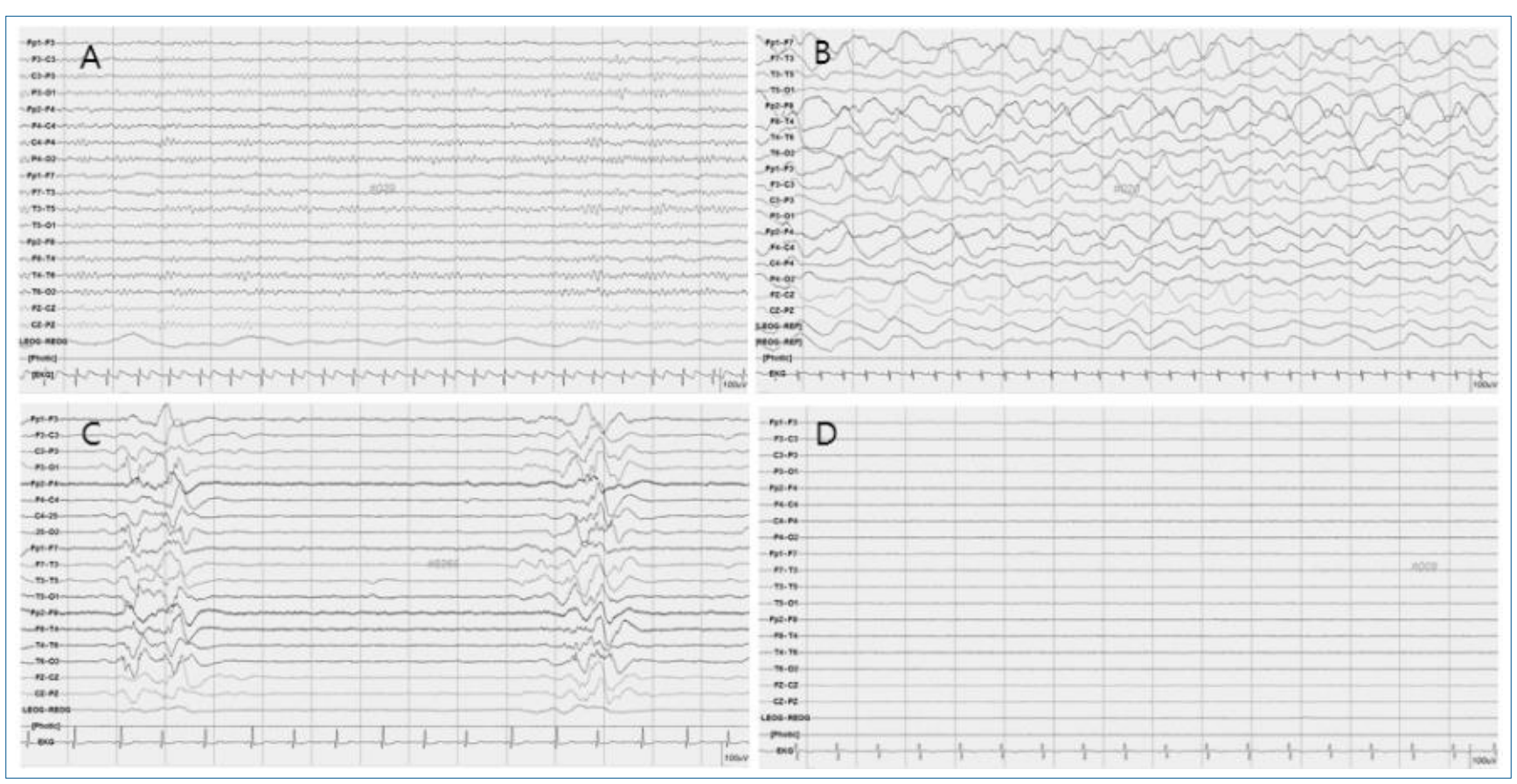

Fig. 1. Electroencephalography background. (A) Normal. (B) Slow-disorganized. (C) Discontinuous or burst-suppression. (D) Featureless. 
$(10-20 \mu \mathrm{V}) .{ }^{13)}$ Westhall et al. ${ }^{14)}$ classified EEG as having highly malignant (suppression, suppression with periodic discharges, or burst-suppression), malignant (periodic or rhythmic patterns, pathological or nonreactive background), and benign (absence of malignant features) patterns. They concluded that a benign EEG pattern was highly predictive of a good outcome. This EEG classification was validated by other studies that found that a highly malignant EEG pattern is a strong predictor of a poor outcome. ${ }^{15,16)}$

In studies on pediatric patients using ACNS EEG terminology, the EEG background was scored as: (1) normal, (2) slow-disorganized, (3) discontinuous or burst-suppression, or (4) featureless (Fig. 1). ${ }^{17-20)}$ In a study that included 128 children, a worsened EEG background was associated with an increased risk of mortality and an unfavorable neurologic outcome. ${ }^{17}$ In another study that included 73 children, a continuous EEG background within 12 hours of ROSC was associated with a good neurologic outcome. ${ }^{18)}$ An earlier study that categorized EEG as 1 (continuous and reactive tracings), 2 (continuous but unreactive tracings), or 3 (discontinuity, burst-suppression, or lack of cerebral activity) concluded that EEG in categories 2 or 3 were associated with a poor outcome regardless of TTM. ${ }^{21)}$

Although further studies on standardized EEG assessment regarding the reactivity, epileptic discharges, or specific EEG patterns are needed, it has been established that a worsened EEG background predicts a poor neurologic outcome in children as in seen in adults. The 2015 AHA guidelines about pediatric advanced life support recommend that EEG performed within 7 days after pediatric cardiac arrest may be considered an accurate tool to prognosticate neurologic outcomes but should not be used as the sole test to do so. ${ }^{22)}$

\section{Neuroimaging}

Neuroimaging, including brain computed tomography (CT) or magnetic resonance imaging (MRI), is performed to define the cause of cardiac arrest, such as intracranial hemorrhage or other structural brain injury. It also provides prognostic information by assessing the degree of brain edema or hypoxic brain injury.

\section{Computed tomography}

On CT, brain edema can be quantified as the gray-white matter ratio (GWR), the ratio of measured Hounsfield units (HU). As brain edema reduces the gray-white matter differentiation, the GWR ratio decreases. There are no standard measurements for GWR, which may be measured in the entire brain with automated assessment or may be measured in regions of interest (ROI) chosen by investigators. ${ }^{23-25)}$ GWR measured at the basal ganglia (BG) showed higher prognostic accuracy than other locations in the brain. ${ }^{26)}$ In commonly used GWR-BG measurements, $\mathrm{HU}$ are obtained in the caudate nucleus $(\mathrm{CN})$, putamen (PU), genu of the corpus callosum (CC), and posterior limb of the internal capsule (PIC) (Fig. 2A). The GWR-BG values are calculated by dividing the $\mathrm{HU}$ value measured in the gray matter by the $\mathrm{HU}$ value in the white matter $(\mathrm{GWR}=[\mathrm{CN}$ $+\mathrm{PU}] /[\mathrm{CC}+\mathrm{PIC}])$. More simplified methods such as CN/PIC, $\mathrm{CN} / \mathrm{CC}$, PU/PIC, or PU/CC are also used. ${ }^{25)} \mathrm{A}$ GWR of less than 1.18 to 1.22 can predict mortality with $100 \%$ specificity in adult patients. $23,25,27)$ The 2015 AHA guidelines for adults recommend the use of a markedly reduced GWR on brain CT obtained within 2 hours after cardiac arrest in patients with a poor prognosis who are not treated with TTM. ${ }^{3)}$

In a retrospective study that included 78 children, the GWR cutoff value of 1.09 in patients $<2$ years and 1.28 in patients $>2$ years predicted mortality with $100 \%$ specificity. ${ }^{28)}$ The study concluded that a marked reduction of GWR, sulcal effacement, basilar cistern effacement, and reversal sign on brain CT scan soon after ROSC was associated with mortality and a poor outcome. ${ }^{28)}$ In another study of 64 children who underwent brain CT within 24 hours of cardiac arrest, a decreased GWR and ambient cistern effacement predicted a poor outcome. ${ }^{29)}$ The study presented a GWR cutoff value of 1.08 as a poor outcome for patients aged $<4$ years and 1.18 for patients aged $\geq 4$ years with $100 \%$ specificity. ${ }^{29)}$

Brain CT studies are mostly retrospective and there is inadequate evidence to determine the timing of brain CT and classify the findings for prognostication. However, brain CT is a convenient scan that can be performed quickly and easily in the emergency room. Brain CT findings indicating severe brain edema or severe diffuse hypoxic injury, including reduced gray to

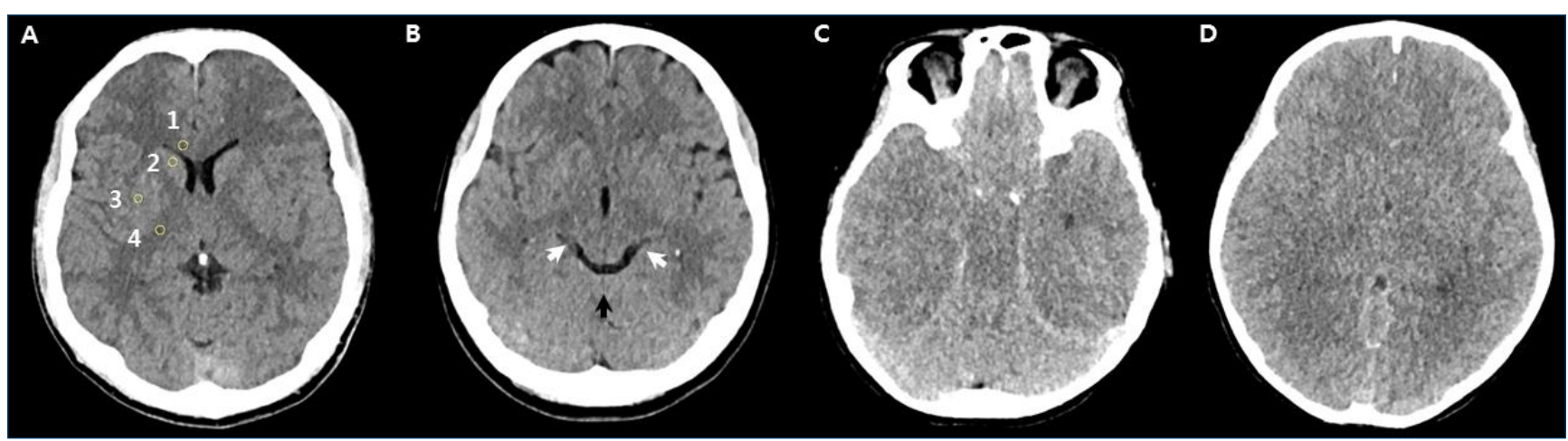

Fig. 2. Brain computed tomography findings. (A) Regions of interest in the basal ganglia level: (1) corpus callosum, (2) caudate nucleus, (3) putamen, and (4) posterior limb of internal capsule. (B) Normal brain computed tomography scan showing basilar cistern (white arrows) and quadrigeminal cistern (black arrow). (C) Reversal sign with a bright cerebellum and dark cortex. (D) Loss of gray-white matter differentiation and sulcal effacement. 
white matter differentiation (Fig. 2D), sulcal effacement, basilar cistern effacement, ambient cistern effacement, and reversal sign (Fig. 2C), can be a poor prognosis factor. Brain CT may help with prognostication when it is considered together with other assessments, such as a clinical neurological examination and EEG.

\section{Magnetic resonance imaging}

Brain MRI is more sensitive than brain CT for detecting hypoxic-ischemic injury. Diffusion-weighted imaging (DWI) sequences show the restriction of water movement that results from brain edema. The apparent diffusion coefficient (ADC) is a quantitative measure of the DWI changes. The 2015 AHA guidelines state that a brain MRI taken 2-6 days after cardiac arrest showing extensive diffusion restriction in combination with other established predictors can predict a poor neurologic outcome. ${ }^{3)}$

In a pediatric study, DWI lesions in the $\mathrm{BG}$ and cerebral cortex of patients with a large number of injured brain regions and a global decrease in measured ADC signal within 1 week after cardiac arrest were associated with a poor outcome. ${ }^{30)}$ In another pediatric study in which brain MRI was performed within 2 weeks of cardiac arrest, increased cerebral blood flow and decreased $\mathrm{ADC}$ were colocalized in the same region in children with poor outcomes. ${ }^{31)}$ Brain MRI frequently involves the risks of sedation and selection bias because unstable patients cannot undergo brain MRI. However, a brain MRI provides detailed information about hypoxic brain injury. In the recent AHA scientific statement for pediatric postcardiac arrest care, brain MRI using conventional imaging and DWI in the first 3-7 days after ROSC was reported helpful for supplementing the clinical assessment and can be used to prognosticate outcomes along with other modalities.5)

\section{Blood biomarkers}

Blood biomarkers that reflect brain injury may be useful for easily quantifying the prognosis. Neuron-specific enolase (NSE) and S-100B are the most commonly examined blood markers. In pediatric studies, elevated levels of NSE and S-100B were reportedly associated with a poor outcome. ${ }^{32-34)}$ However, comprehensive studies to identify timing and threshold values are needed in the future. The 2015 AHA guidelines for adults do not recommend the use of blood levels of NSE and S-100B alone to predict a poor outcome because of the high possibility of a false positive result. ${ }^{3)}$ The 2015 ERC/ESICM guidelines for adults state that increasing levels of NSE over time may have added value for predicting a poor outcome. ${ }^{4)}$ NSE and S-100B can be produced by other conditions such as hemolysis, neuroendocrine tumors, and muscle breakdown in addition to neuronal damage. Therefore, clinical situations should be carefully considered when blood biomarkers are used as prognostic factors.

\section{Multimodal prognostication}

Although prognostic modalities are advanced and some predictors showed no false positives in some studies, no single test can accurately predict outcomes in children after cardiac arrest. Recent studies showed that a multimodal prognostication

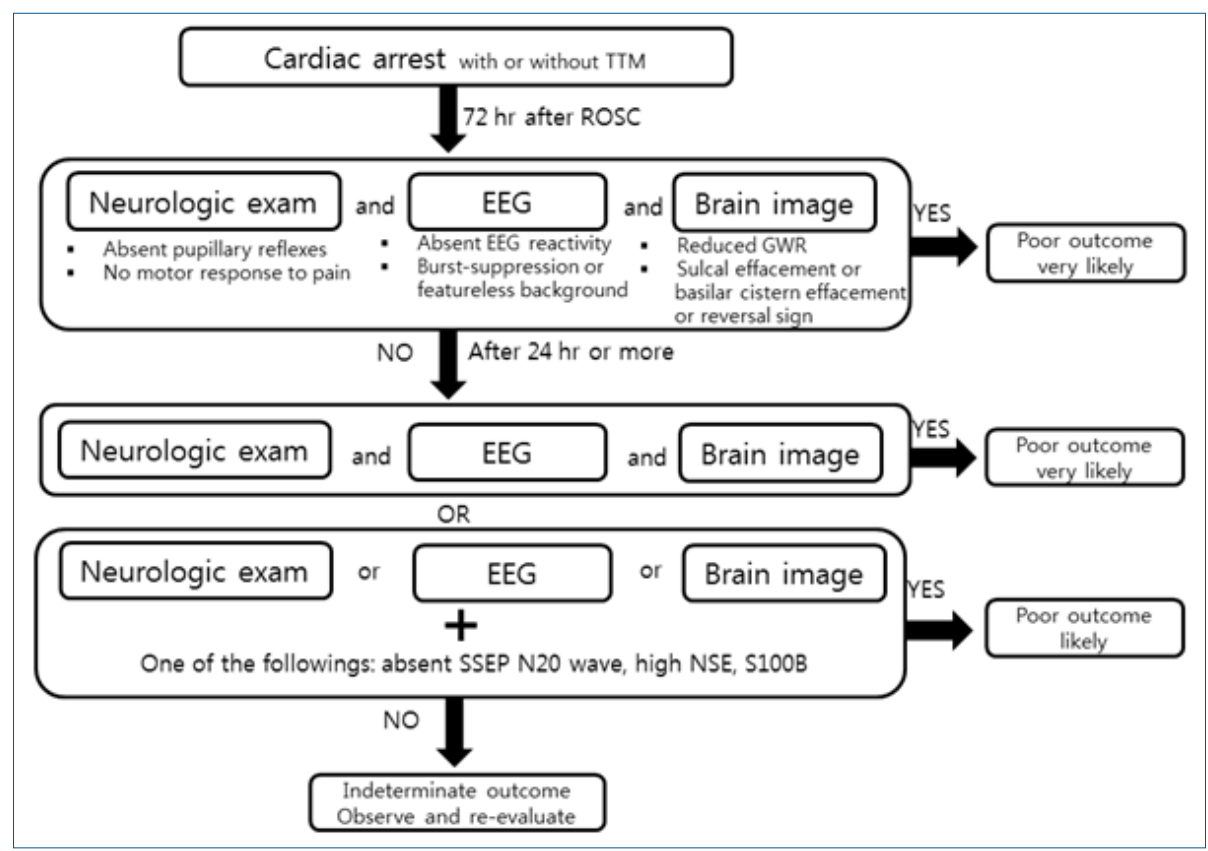

Fig. 3. Multimodal prognostication strategy. A patient who shows robust signs of a poor prognosis in all 3 modalities is likely to have a poor outcome. If the repeated assessment does not fulfill 3 robust signs, a patient showing less robust signs is likely to have a poor outcome. TTM, targeted temperature management; ROSC, return of spontaneous circulation; EEG, electroencephalography; GWR, gray-white matter ratio; SSEP, somatosensory-evoked potentials; NSE, neuron-specific enolase. 
provides a more accurate predictive value than a single modality. $20,29,35)$ The combination of neurologic examination, brain imaging, and an EEG or blood test can reduce false prognostication.

Considering the previous studies and guidelines, we suggest a prognostication strategy for comatose pediatric patients who have been resuscitated from cardiac arrest (Fig. 3). Patients who remain comatose with an absent extensor motor response to pain at 72 hours or more after ROSC, without other confounding factors such as sedatives or metabolic derangement, are eligible for prognostication. If the sedation is prolonged or patients are medically unstable, the prognostication timing should be delayed. The patient who shows robust signs of poor prognosis in all 3 modalities (neurological examination, EEG, and brain CT) is likely to have a poor outcome. If a patient fulfills at least one robust sign of poor prognosis, the assessment should be repeated. If the repeated assessment fulfills 3 robust signs, the patient likely has a poor outcome. If the repeated assessment does not fulfill 3 robust signs, the patient showing less robust signs, including the absence of N20 SSPE waves and a high level of NSE or S100B, is likely to have a poor outcome (Fig. 3).

\section{Conclusion}

Predicting the neurologic outcome in comatose pediatric patients resuscitated from cardiac arrest remains a challenge. The principles of prognostication are that the assessment timing should be multimodal and delayed until at least 72 hours after cardiac arrest. In future studies, the referred modalities should be validated in detail using a larger cohort of children and the suggested prognostication strategy should be further verified. Additional tools that are currently under investigation may also improve the prognostication of such patients.

\section{Conflict of interest}

The authors report no potential conflicts of interest relevant to this article.

See the commentary "Targeted temperature management and neuroprotective outcomes of pediatric patients after cardiac arrest" via https://doi.org/10.3345/cep.2019.01396.

\section{References}

1. Fink EL, Prince DK, Kaltman JR, Atkins DL, Austin M, Warden C, et al. Unchanged pediatric out-of-hospital cardiac arrest incidence and survival rates with regional variation in North America. Resuscitation 2016;107: 121-8.

2. Ahn JY, Lee MJ, Kim H, Yoon HD, Jang HY. Epidemiological and survival trends of pediatric cardiac arrests in Emergency Departments in Korea: a cross-sectional, nationwide report. J Korean Med Sci 2015;30:1354-60.

3. Callaway CW, Donnino MW, Fink EL, Geocadin RG, Golan E, Kern KB, et al. Part 8: Post-cardiac arrest care: 2015 American Heart Association Guidelines update for cardiopulmonary resuscitation and emergency cardiovascular care. Circulation 2015;132(18 Suppl 2):S465-82.
4. Nolan JP, Soar J, Cariou A, Cronberg T, Moulaert VR, Deakin CD, et al. European Resuscitation Council and European Society of Intensive Care Medicine Guidelines for post-resuscitation care 2015: section 5 of the European Resuscitation Council Guidelines for resuscitation 2015. Resuscitation 2015;95:202-22.

5. Topjian AA, de Caen A, Wainwright MS, Abella BS, Abend NS, Atkins DL, et al. Pediatric post-cardiac arrest care: a scientific statement from the American Heart Association. Circulation 2019; 140:e194-e233.

6. Fiser DH. Assessing the outcome of pediatric intensive care. J Pediatr 1992;121:68-74.

7. Fiser DH, Long N, Roberson PK, Hefley G, Zolten K, Brodie-Fowler M. Relationship of pediatric overall performance category and pediatric cerebral performance category scores at pediatric intensive care unit discharge with outcome measures collected at hospital discharge and 1- and 6-month follow-up assessments. Crit Care Med 2000;28:2616-20.

8. Pollack MM, Holubkov R, Glass P, Dean JM, Meert KL, Zimmerman J, et al. Functional Status Scale: new pediatric outcome measure. Pediatrics 2009;124:e18-28.

9. Wijdicks EF, Hijdra A, Young GB, Bassetti CL, Wiebe S; Quality Standards Subcommittee of the American Academy of Neurology. Practice parameter: prediction of outcome in comatose survivors after cardiopulmonary resuscitation (an evidence-based review): report of the Quality Standards Subcommittee of the American Academy of Neurology. Neurology 2006;67:203-10.

10. Mandel R, Martinot A, Delepoulle F, Lamblin MD, Laureau E, Vallee L, et al. Prediction of outcome after hypoxic-ischemic encephalopathy: a prospective clinical and electrophysiologic study. J Pediatr 2002;141:4550.

11. Abend NS, Topjian AA, Kessler SK, Gutierrez-Colina AM, Berg RA, Nadkarni V, et al. Outcome prediction by motor and pupillary responses in children treated with therapeutic hypothermia after cardiac arrest. Pediatr Crit Care Med 2012;13:32-8.

12. Herman ST, Abend NS, Bleck TP, Chapman KE, Drislane FW, Emerson $\mathrm{RG}$, et al. Consensus statement on continuous EEG in critically ill adults and children, part I: indications. J Clin Neurophysiol 2015;32:87-95.

13. Hirsch LJ, LaRoche SM, Gaspard N, Gerard E, Svoronos A, Herman ST, et al. American Clinical Neurophysiology Society's Standardized Critical Care EEG Terminology: 2012 version. J Clin Neurophysiol 2013;30:127.

14. Westhall E, Rossetti AO, van Rootselaar AF, Wesenberg Kjaer T, Horn J, Ullén $S$, et al. Standardized EEG interpretation accurately predicts prognosis after cardiac arrest. Neurology 2016;86:1482-90.

15. Backman S, Cronberg T, Friberg H, Ullén S, Horn J, Kjaergaard J, et al. Highly malignant routine EEG predicts poor prognosis after cardiac arrest in the Target Temperature Management trial. Resuscitation 2018;131:248.

16. Beuchat I, Solari D, Novy J, Oddo M, Rossetti AO. Standardized EEG interpretation in patients after cardiac arrest: Correlation with other prognostic predictors. Resuscitation 2018;126:143-6.

17. Topjian AA, Sánchez SM, Shults J, Berg RA, Dlugos DJ, Abend NS. Early electroencephalographic background features predict outcomes in children resuscitated from cardiac arrest. Pediatr Crit Care Med 2016; 17:547-57.

18. Ostendorf AP, Hartman ME, Friess SH. Early electroencephalographic findings correlate with neurologic outcome in children following cardiac arrest. Pediatr Crit Care Med 2016;17:667-76.

19. Abend NS, Massey SL, Fitzgerald M, Fung F, Atkin NJ, Xiao R, et al. Interrater agreement of EEG interpretation after pediatric cardiac arrest using standardized critical care EEG terminology. J Clin Neurophysiol 2017;34:534-41.

20. Yang D, Ryoo E, Kim HJ. Combination of early EEG, brain CT, and ammonia level is useful to predict neurologic outcome in children resuscitated from cardiac arrest. Front Pediatr 2019;7:223.

21. Kessler SK, Topjian AA, Gutierrez-Colina AM, Ichord RN, Donnelly M, Nadkarni VM, et al. Short-term outcome prediction by electroencephalographic features in children treated with therapeutic hypothermia after cardiac arrest. Neurocrit Care 2011;14:37-43. 
22. de Caen AR, Berg MD, Chameides L, Gooden CK, Hickey RW, Scott HF, et al. Part 12: Pediatric Advanced Life Support: 2015 American Heart Association Guidelines update for cardiopulmonary resuscitation and emergency cardiovascular care. Circulation 2015;132(18 Suppl 2):S52642.

23. Metter RB, Rittenberger JC, Guyette FX, Callaway CW. Association between a quantitative CT scan measure of brain edema and outcome after cardiac arrest. Resuscitation 2011;82:1180-5.

24. Hanning U, Sporns PB, Lebiedz P, Niederstadt T, Zoubi T, Schmidt R, et al. Automated assessment of early hypoxic brain edema in non-enhanced CT predicts outcome in patients after cardiac arrest. Resuscitation 2016; 104:91-4.

25. Gentsch A, Storm C, Leithner C, Schroeder T, Ploner CJ, Hamm B, et al. Outcome prediction in patients after cardiac arrest: a simplified method for determination of gray-white matter ratio in cranial computed tomography. Clin Neuroradiol 2015;25:49-54.

26. Na MK, Kim W, Lim TH, Jang B, Cho Y, Choi KS, et al. Gray matter to white matter ratio for predicting neurological outcomes in patients treated with target temperature management after cardiac arrest: a systematic review and meta-analysis. Resuscitation 2018;132:21-8.

27. Choi SP, Park HK, Park KN, Kim YM, Ahn KJ, Choi KH, et al. The density ratio of grey to white matter on computed tomography as an early predictor of vegetative state or death after cardiac arrest. Emerg Med J 2008;25:666-9.

28. Starling RM, Shekdar K, Licht D, Nadkarni VM, Berg RA, Topjian AA. Early head CT findings are associated with outcomes after pediatric out- of-hospital cardiac arrest. Pediatr Crit Care Med 2015;16:542-8.

29. Yang D, Ha SG, Ryoo E, Choi JY, Kim HJ. Multimodal assessment using early brain $\mathrm{CT}$ and blood $\mathrm{pH}$ improve prediction of neurologic outcomes after pediatric cardiac arrest. Resuscitation 2019;137:7-13.

30. Oualha M, Gatterre P, Boddaert N, Dupic L, De Saint Blanquat L, Hubert $\mathrm{P}$, et al. Early diffusion-weighted magnetic resonance imaging in children after cardiac arrest may provide valuable prognostic information on clinical outcome. Intensive Care Med 2013;39:1306-12.

31. Manchester LC, Lee V, Schmithorst V, Kochanek PM, Panigrahy A, Fink EL. Global and regional derangements of cerebral blood flow and diffusion magnetic resonance imaging after pediatric cardiac arrest. J Pediatr 2016;169:28-35.e1.

32. Fink EL, Berger RP, Clark RS, Watson RS, Angus DC, Richichi R, et al. Serum biomarkers of brain injury to classify outcome after pediatric cardiac arrest. Crit Care Med 2014;42:664-74.

33. Topjian AA, Lin R, Morris MC, Ichord R, Drott H, Bayer CR, et al. Neuron-specific enolase and S-100B are associated with neurologic outcome after pediatric cardiac arrest. Pediatr Crit Care Med 2009;10: 479-90.

34. Kramer P, Miera O, Berger F, Schmitt K. Prognostic value of serum biomarkers of cerebral injury in classifying neurological outcome after paediatric resuscitation. Resuscitation 2018;122:113-20.

35. Youn CS, Callaway CW, Rittenberger JC; Post Cardiac Arrest Service. Combination of initial neurologic examination, quantitative brain imag. ing and electroencephalography to predict outcome after cardiac arrest. Resuscitation 2017;110:120-5. 